\title{
Faces of Lyme
}

\author{
Debbie C. Chen, $\mathrm{MD}^{7}$, Brandon M. Giglio, $\mathrm{MD}^{7}$, and Paul B. Aronowitz, $\mathrm{MD}^{2}$ \\ 'Department of Internal Medicine, Massachusetts General Hospital, Boston, MA, USA; ${ }^{2}$ Department of Internal Medicine, University of California, \\ Davis School of Medicine, Sacramento, CA, USA.
}

KEY WORDS: clinical image; infectious disease; dermatology; diagnosis. J Gen Intern Med 32(5):583-4

DOI: $10.1007 /$ s11606-016-3939-0

(C) Society of General Internal Medicine 2016

Patient 1. A 59-year-old male presented to clinic with 1 week of fatigue and chills after hiking in eastern Massachusetts 6 weeks prior to presentation. He recalled removing a tick from his left hip during the hike and subsequently noticed a new rash in that same location. Physical examination revealed a 5-cm circular, erythematous patch with violaceous center on his left hip (Fig. 1a).

Patient 2. A 56-year-old male presented to the emergency department with 3 days of malaise and rash. He had spent time at a barbecue in Massachusetts 5 days earlier, but did not recall any insect or tick bites. Physical examination revealed a $10-\mathrm{cm}$ oval-shaped erythematous, non-tender plaque with vesiculobullous surface in the left popliteal fossa with surrounding erythema (Fig. 1b).

Both patients experienced complete resolution of symptoms and rash after receiving 21 days of doxycycline for treatment of presumed Lyme disease. While erythema migrans is present in up to $80 \%$ of patients with Lyme disease ${ }^{1}$, only $9 \%$ present with classic central clearing $^{2}$. Given the poor sensitivity $(<40 \%)$ of serological testing in patients with erythema migrans ${ }^{1,3,4}$, the diagnosis and prompt treatment of Lyme disease often depend on physicians' ability to recognize its varied cutaneous manifestations.

Received October 26, 2016

Revised November 17, 2016

Accepted November 22, 2016

Published online December 12, 2016
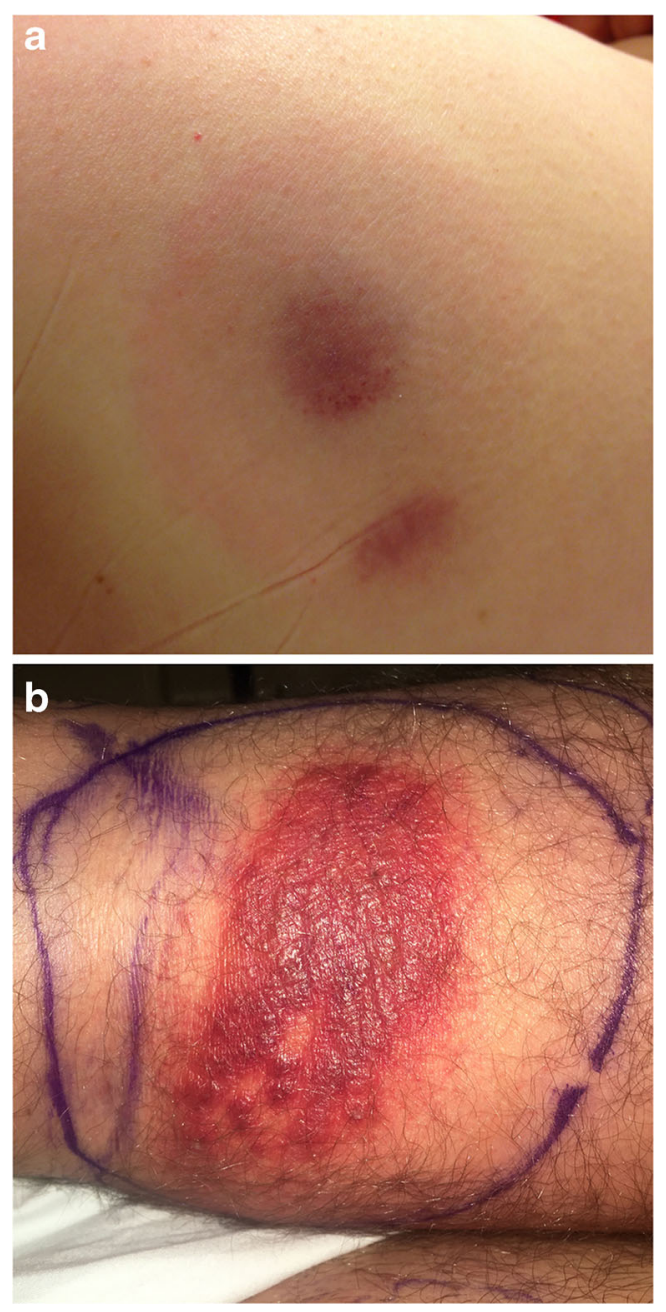

Figure 1 Two variants of erythema migrans. a Erythema migrans on the left hip in a 59-year-old male (patient 1) manifesting as a circular erythematous patch with violaceous center. b Bullous erythema migrans in the left popliteal fossa in a 56-year-old male (patient 2) manifesting as an oval erythematous plaque with diffuse coalescing vesicles and bullae and surrounding erythema.

Corresponding Author: Paul B. Aronowitz, MD; Department of Internal MedicineUniversity of California, Davis School of Medicine, Sacramento, CA, USA (e-mail: Paronowitz@ucdavis.edu).

\section{Compliance with Ethical Standards:}

Conflicts of Interest: The authors declare that they do not have any conflicts of interest.

\section{Funding: None}




\section{REFERENCES}

1. Sanchez E, Vannier E, Wormser GP, Hu LT. Diagnosis, treatment, and prevention of Lyme disease, human granulocytic anaplasmosis, and babesiosis: a review. JAMA. 2016;315(16):1767-1777. doi:10.1001/jama. 2016.2884 .

2. Smith RP, Schoen RT, Rahn DW, et al. Clinical characteristics and treatment outcome of early Lyme disease in patients with microbiologically confirmed erythema migrans. Ann Intern Med. 2002;136(6):42 1-428.

3. Tibbles CD, Edlow JA. Does this patient have erythema migrans? JAMA. 2007;297(23):2617-2627. doi:10.1001/jama.297.23.2617.

4. Paul S, Song PI, Ogbechie OA, et al. Vesiculobullous and hemorrhagic erythema migrans: uncommon variants of a common disease. Int $J$ Dermatol. 2016;55(2):e79-e82. doi:10.1111/ ijd. 12927. 